\title{
Endotracheal Intubation before Percutaneous Coronary Intervention
}

National Cancer Institute

\section{Source}

National Cancer Institute. Endotracheal Intubation before Percutaneous Coronary

Intervention. NCI Thesaurus. Code C99950.

Endotracheal intubation which occurs before a percutaneous coronary intervention can take place. (ACC) 